\title{
Riluzole, a Novel Antiglutamate, Prevents Memory Loss and Hippocampal Neuronal Damage in Ischemic Gerbils
}

\author{
Christiane Malgouris, ${ }^{1}$ Florence Bardot, ${ }^{1}$ Marc Daniel,, Fabienne Pellis, ${ }^{1}$ Jean Rataud, ${ }^{1}$ André Uzan, ${ }^{1}$ Jean- \\ Charles Blanchard, ${ }^{2}$ and Pierre M. Laduron ${ }^{2}$ \\ 'Rhône-Poulenc Santé, Centre de Recherches de Gennevilliers, 92231 Gennevilliers Cedex, France, Rhône-Poulenc \\ Santé Centre de Recherches de Vitry, 94403 Vitry-sur-Seine Cedex, France
}

The neuroprotective effects of riluzole, a novel antiglutamate, has been demonstrated in a model of ischemia induced in female Mongolian gerbils by transient bilateral carotid occlusion. Riluzole was administered at a dose of 4 $\mathrm{mg} / \mathrm{kg}$, i.p., just before, $4 \mathrm{hr}$ after, and for the $14 \mathrm{~d}$ following the transient bilateral carotid occlusion $(10 \mathrm{~min})$. The functional sequelae of ischemic damage were assessed using a memory test (passive avoidance) and the extent of neuronal damage by histological examination and quantitative autoradiography of muscarinic cholinergic receptors in the hippocampus. The performance of the ischemic gerbils in the memory test was about half that of control animals. This memory deficit was completely reversed in animals treated with riluzole. This protective effect of riluzole was confirmed by histological and autoradiographic studies.

The neuronal degeneration of CA1 pyramidal cells In the hippocampus observed in the ischemic group was not seen in the riluzole-treated animals, which resembled the control group. This neuronal degeneration in the CA1 area was confirmed by a quantitative measurement of muscarinic receptors: The binding was decreased by a third in the lacunosum moleculare, the stratum oriens, and the stratum radiatum. By contrast in riluzole-treated gerbils, this decrease was reversed by $\mathbf{5 0} \%$. Finally, a clear-cut correlation was found between the deficit in the memory test and the decrease in muscarinic receptor binding in the CA1 fields.

These results are compatible with the idea that glutamic acid may be involved in the neuronal degeneration of the hippocampus following ischemia, and could be foreseeable. The major finding of this work is that riluzole, a novel antiglutamate, protects the brain from both the cellular and functlonal consequences of ischemia.

The excitatory amino acids, particularly glutamic acid, seem to play a key role in the pathogenesis of brain damage following cerebral ischemia and in certain neurological diseases (Rothman, 1984; Hagberg et al., 1985; Rothman and Olney, 1986). The consequences of an abrupt interruption of the cerebral circulation involve cessation of electrical activity, ion loss, deple-

\footnotetext{
Received Jan. 27, 1989; accepted Mar. 9, 1989.

We wish to thank Dr. A. Doble for stylistic revision, Mrs. B. Gegu for her excellent technical assistance, and Mrs. J. Daout for preparing the manuscript.

Correspondence should be addressed to C. Malgouris, Rhône-Poulenc Santé, Centre de Recherches de Vitry-Alfortville, 13, quai Jules Guesde, BP 14, F-94403 Vitry-sur-Seine Cedex, France.

Copyright $(C) 1989$ Society for Neuroscience $0270-6474 / 89 / 113720-08 \$ 02.00 / 0$
}

tion of high-energy phosphates, potassium efflux, sodium influx, and membrane depolarization. This can lead to an excessive release of endogenous excitatory amino acids such as glutamic acid, which are probably responsible for irreversible cell damage (Siesjö, 1981; Wieloch and Siesjö, 1982).

Transient forebrain ischemia induces neuronal damage in specific brain areas in rat (Pulsinelli et al., 1982; Smith et al., 1984) and in Mongolian gerbil, which is a very sensitive model of ischemia insult (Levine and Payan, 1966; Jarrot and Domer, 1980). Neuronal degenerative process occurs especially in the hippocampus, where the pyramidal cells in the CA1 subfields seem to be the most sensitive to ischemia (Kirino, 1982). The excitatory input to CAl pyramidal cells coming from the CA3 subfield may be critical for the neuronal damage observed after carotid occlusion (Onodera et al., 1986). Perhaps the most sensitive index for this neuronal damage is the loss of muscarinic receptors in the CAl area, which occurs before neuronal death (Onodera et al., 1987).

Riluzole (2-amino-6-trifluoromethoxy benzothiazole PK 26124, RP 54274) was first described as an anticonvulsant compound (Benavides et al., 1985; Mizoule et al., 1985). Since this drug protected animals against convulsions induced by glutamic acid and glutamic acid decarboxylase inhibitors, it was considered to interfere with glutamatergic neurotransmission. Unlike other described glutamic acid antagonists such $(+) 5$ methyl10,11-dihydro-5H-dibenzo[a,d]cyclo-hepten-5,10-imine (MK 801) and 3-(2-carboxypiperazin-4-yl)propyl-1-phosphonic acid (CPP), riluzole does not bind to any of the known subtypes of excitatory amino acid receptors. Riluzole has, however, been shown to inhibit glutamic acid release from nerve terminals (Cheramy et al., 1986; Drejer et al., 1986; Doble et al., 1987). This compound might thus be considered as an indirectly acting antiglutamate. Riluzole has since been found to improve sleep quality in rats mainly by increasing REM sleep (Stutzmann et al., 1988). Since it has been suggested many times that drugs that prevent glutamate release or block its postsynaptic action may protect central mammalian neurons from ischemic injury (Evans et al., 1984; Simon et al., 1984; Rothman and Olney, 1986), it was evident that this new antiglutamate should be active in ischemia. Therefore, we decided to test riluzole in ischemia.

We now report on the effects of riluzole on the memory deficit and neuronal damage induced in gerbils by carotid occlusion.

\section{Materials and Methods}

Preparation of ischemic animals. Female Mongolian gerbils (Meriones unguiculatus) weighing 55-65 gm were supplied by Janvier (France). 
Bilateral carotid occlusion was performed in animals anesthetized with ketamine $(80 \mathrm{mg} / \mathrm{kg}$, i.p.). After ventral cervical incision, the left and right common carotid arteries were exposed in the parabracheal region and carefully separated from the adjacent vein and sympathetic nerves. A loose ligature was placed around the artery in order to facilitate its identification.

Both arteries were then clamped with microvascular clips (Moria, France) for $10 \mathrm{~min}$. After the clips were removed to restore blood flow, the skin was sutured and the wound treated with an antibiotic spray (chloramphenicol, Roussel UCLAF, France). The animals were housed individually and allowed free access to food and water. Sham-operated animals (control) were trcated as were the ischemic gerbils except for clamping.

Experiments were performed on $\mathbf{4 5}$ gerbils which were divided into 3 groups of 15 animals: control, ischemic and ischemic riluzole-treated. A control experiment was carried out on 14 gerbils divided into 2 groups of 7 animals: control and control riluzole-treated.

Drug administration. Riluzole was dissolved in a solvent containing $0.9 \% \mathrm{NaCl}$ and $4 \% \mathrm{HCl} 0.1 N(\mathrm{pH} 3.5)$. Riluzole, $4 \mathrm{mg} / \mathrm{kg}$, or solvent (maximal volume, $10 \mathrm{ml} / \mathrm{kg}$ ) as injected intraperitoneally $15 \mathrm{~min}$ before and $4 \mathrm{hr}$ after carotid occlusion. The animals also received riluzole at the same dose twice daily for a further $14 \mathrm{~d}$ after carotid occlusion. The control and the ischemic gerbil groups received the solvent in the same way as the riluzole-treated animals.

Three gerbils died after surgery ( 1 in the control group and 2 in the ischemic group); no mortality was observed in the riluzole group. Carotid occlusion did not induce seizures or any other abnormal behavior in the survivors.

Passive avoidance test. The passive avoidance tesl described by Araki et al. (1987) was carried out in all animals $14 \mathrm{~d}$ after surgery. The gerbils were trained in a conventional step-down passive avoidance apparatus, divided into a safe compartment and a grid compartment. The floor had a grid of brass rods, and a $50 \mathrm{~V}(1 \mathrm{~Hz}, 100 \mathrm{msec})$ shock was delivered by means of a constant direct current shock generator. The safe part $(22.0 \times 9.5 \times 3.0 \mathrm{~cm})$ was insulated by means of a Plexiglas sheet on the grid floor.

At the beginning of the test, each animal was placed on the safety platform. When the gerbil stepped down onto the grid floor, it received a foot shock. Although the gerbils repeatedly stepped up and down, they learned to remain on the platform. This training session lasted $5 \mathrm{~min}$. The test trial was performed $24 \mathrm{hr}$ after the training session. The gerbils were placed on the safety platform and the response latency, i.e., the time before it stepped down onto the grid floor, was measured. If the gerbil did not step down to the grid floor within $60 \mathrm{sec}$, a ceiling score of $60 \mathrm{sec}$ was assigned.

Histopathology and autoradiography. On day 16, the animals were decapitated for histology and receptor autoradiography; the brains were removed immediately, rapidly frozen, and kept at $-80^{\circ} \mathrm{C}$ for histology and autoradiography.

Serial coronal sections $(10 \mu \mathrm{m})$, cut using a Leitz 1720 cryostat microtome at $-20^{\circ} \mathrm{C}$, were thaw-mounted onto gelatin-coated slides and stored at $-20^{\circ} \mathrm{C}$ until used. Adjacent sections $(40 \mu \mathrm{m})$ were stained with cresyl violet by the method of Paxinos and Watson (1986) for histopathological examination.

${ }^{3} \mathrm{H}$-quimuclidinyl benzilate ( ${ }^{3} \mathrm{H}-\mathrm{QNB}$, New England Nuclear) was used as a ligand to label muscarinic receptors according to a modification of the method of Wamsley et al. (1984). Briefly, brain sections were incubated with $1 \mathrm{nM}{ }^{3} \mathrm{H}-\mathrm{QNB}(43 \mathrm{Ci} / \mathrm{mmol})$ in phosphate buffer $(\mathrm{pH} 7.4)$ for $120 \mathrm{~min}$ at room temperature. After incubation, the sections were rinsed twice in buffer for $5 \mathrm{~min}$ at $4^{\circ} \mathrm{C}$, then washed quickly in distilled water and dried under a stream of cold air. Nondisplaceable (nonspecific) binding was determined in the presence of $1 \mu \mathrm{M}$ atropine.

Labeled tissue sections were kept in contact with LKB 3H Ultrofilm for $11 \mathrm{~d}$, together with appropriate tritium standards (Amersham, ${ }^{3} \mathrm{H}$ microscales). The films were then quantified using a computerized image analysis system (Quantimet 970-Cambridge Instruments). The optical densities measured throughout the study were in the range where the relationship between radioactivity and optical density was linear.

Preliminary experiments were carried out in parasagittal sections in order to determine the binding characteristics of the ${ }^{3} \mathrm{H}-\mathrm{QNB}$ sites. After incubation in the binding assay, the sections were washed as previously described and wiped off with Whatman GF/B filters. The sections were then placed in vials with scintillant (Instagel Packard) and counted for radioactivity in a liquid scintillation spectrometer.

${ }^{3} \mathrm{H}-\mathrm{QNB}$ binding reached equilibrium in $90 \mathrm{~min}$, and $95 \%$ of bound
QNB was displaced by addition of $1 \mu \mathrm{M}$ atropine. Scatchard analysis revealed a single class of receptor sites for ${ }^{3} \mathrm{H}-\mathrm{QNB}$ with an affinity constant of $0.25 \mathrm{nM}$ and a maximal number of receptor sites of 0.5 $\mathrm{pmol} / \mathrm{mg}$ protein, which are very similar to values reported in the literature (Kuhar and Yamamura, 1976).

A possible drawback with quantitative autoradiography may be a change in the quenching level after ischemia. As discussed in detail in Onodera et al. (1987), there was no need to make a quenching correction because of increased gliosis.

Presentation of results and statistical analysis. In the passive avoidance test, time latency was expressed in seconds. Results were means \pm SEM of the time latency and the number of step-through respectively obtained from each animal per group. Statistical analysis was carried out using 1-way analysis of variance followed by Student's $t$ test or Wilcoxon's test (for heterogeneous variance). The ischemic group was compared with the control group, and the ischemic riluzole-treated group to the untreated ischemic group. The control riluzole-treated group was compared with the respective control group.

For quantitative autoradiography, optical densities were measured bilaterally in each hippocampal subregion. Nine brain sections were analyzed from each gerbil. The tissue concentrations of ${ }^{3} \mathrm{H}-\mathrm{QNB}$ (expressed as $\mathrm{pmol} / \mathrm{mg}$ protein) were determined from their optical densities by comparison with the optical densities of calibrated ${ }^{3} \mathrm{H} \mathrm{mi-}$ croscale standards (ranging from equivalent tissue concentrations of 0.06-6.31 pmol $/ \mathrm{mg}$ protein).

The changes induced by carotid occlusion were calculated with respect to control animals and the protective effect of riluzole in ischemic gerbils with respect to the untreated animals. Statistical analysis was performed using 1-way analysis of variance followed by Student's $t$ test or Wilcoxon's test (for heterogeneous variance).

In some experiments, the difference between control (C) and ischemic (I) animals was calculated as a percentage of binding loss obtained in untreated ischemic animals as compared with naive animals. The percentage of binding loss in riluzole treated gerbils $(\mathrm{R})$ was calculated as follows:

$$
(\mathrm{C}-\mathrm{R}) /(\mathrm{C}-\mathrm{I}) \times 100 .
$$

The correlation coefficient between time latency in passive avoidance and the number of muscarinic cholinergic receptors was derived by linear-regression analysis using the least-squares method.

For the ischemic group, individual values were included in the correlation study. For the control and the ischemic riluzole-treated groups, mean values of time latency and ${ }^{3} \mathrm{H}-\mathrm{QN} B$ binding sites were used, respectively. Indeed, in both these groups many gerbils reached the time latency ceiling score, whereas their respective muscarinic cholinergic binding sites values were not all equivalent owing to the fact that quantitative autoradiography of ${ }^{3} \mathrm{H}-\mathrm{QNB}$ binding sites is a more sensitive evaluation of ischemic damage than the passive avoidance test.

\section{Results}

Passive avoidance

Preliminary experiments showed that the response latency was impaired markedly in gerbils rendered ischemic by means of transient carotid occlusion; in control animals, the latency time was $46.2 \pm 4.9 \mathrm{sec}$ and, in ischemic gerbils, $29.0 \pm 6.4 \mathrm{sec}$ (Table 1). A shortened latency time therefore corresponds to a memory loss. The capacity of riluzole to restore the memory loss in ischemic gerbils was then evaluated.

In order to exclude a possible interaction of riluzole on the response latency, relevant control experiments were performed; there was no significant modification of time latency between control gerbils and control gerbils treated by riluzole (Table 1).

Table 1 shows that riluzole at a dose of $4 \mathrm{mg} / \mathrm{kg}$, i.p., completely prevented the reduction of latency time that was normally seen in untreated ischemic animals: When the drug was administered $15 \mathrm{~min}$ before arterial occlusion and then twice daily for a further $14 \mathrm{~d}$, the latency time recovered to $52.1 \pm$ $4.0 \mathrm{sec}$, a value very similar to that in controls but significantly different from that obtained in untreated ischemic gerbils (Table 1). 


\begin{tabular}{llll}
\hline Table 1. Effects of riluzole in the passive avoidance test in gerbils & \\
& $\begin{array}{l}\text { Dose } \\
(\mathrm{mg} / \mathrm{kg}, \mathrm{i} . \mathrm{p} .)\end{array}$ & $\begin{array}{l}\text { Number of } \\
\text { step-through }\end{array}$ & Time latency $(\mathrm{sec})$ \\
\hline Treatment & & & \\
\hline $\begin{array}{l}\text { Postocclusion } \\
\quad \text { Control }(n=14)\end{array}$ & - & $4.0 \pm 0.7$ & $46.2 \pm 4.9$ \\
$\quad$ Ischemic $(n=13)$ & - & $6.0 \pm 0.8$ & $29.0 \pm 6.4 \quad(p=0.057)$ \\
$\quad$ Ischemic + riluzole $(n=15)$ & 4 & $5.3 \pm 0.6$ & $52.1 \pm 4.0^{*}(p=0.008)$ \\
Control experiments & & & \\
$\quad$ Control $(n=7)$ & - & $5.0 \pm 0.9$ & $59.1 \pm 0.9$ \\
Control + riluzole $(n=7)$ & 4 & $4.0 \pm 0.8$ & $54.4 \pm 2.8$
\end{tabular}

Each value represents the means of $n$ animals (means \pm SEM). Ischemic group was compared with control group. Ischemic riluzole-treated animals were significantly different from untreated ischemic animals $\left({ }^{*} p<0.01\right)$.

The number of step-through observed for each group of gerbils, which corresponds to the number of shocks administered during the training session, was included in Table 1. It was found that no significant differences appeared in learning the task in both groups of riluzole-treated animals, which excludes a possible sedative effect of this compound at this dose.

Nevertheless, the number of step-through was slightly, but not significantly, increased in ischemic gerbils (Table 1) compared with control gerbils. This increase could be due to a memory deficit rather than a hyperactivity of ischemic animals because the training session was performed $14 \mathrm{~d}$ after bilateral carotid occlusion.

\section{Histopathological analysis}

Sixteen days after bilateral carotid occlusion, a marked neuronal degeneration was observed in the CAl subfields in the hippocampus (oriens, radiatum, and lacunosum moleculare) in ischemic gerbils. Figure 1 shows that necrosis was almost total in the pyramidal cells of the CAl region of the hippocampus. Riluzole was found to prevent this necrosis (Fig. 1C), and, in these animals, the Nissl staining in the hippocampal CAl area did not differ markedly from that observed in the sham-operated animals (Fig. $1 \mathrm{~A}$ ). In contrast, there was no visible damage to the pyramidal cells in CA3 nor to granule cells in the dentatc gyrus in the ischemic gerbils, irrespective of whether they had been treated. Histopathological examination of ischemic and riluzole-treated brain sections revealed no significant change in either the caudate putamen, the cortex, or other brain structures.

\section{Autoradiography of muscarinic receptors}

In the same animals, muscarinic cholinergic receptors were studied by quantitative autoradiography using ${ }^{3} \mathrm{H}-\mathrm{QNB}$ binding. In brain sections of control gerbils (Fig. 2, $A, B$ ), a very high density of binding sites was observed in the hippocampal formation, cortical layers (1-4), and in the caudate-putamen. The anterodorsal and anteroventral dorsomedian thalamic nuclei, and the superficial layer of the superior colliculus also contained a high number of ${ }^{3} \mathrm{H}-\mathrm{QNB}$ binding sites. In the present study, densitometric analysis of autoradiograms was focused mainly on the hippocampal formation (from the anterior part to the posterior part) (Table 2).

In the hippocampus of control gerbils, the grain density was much higher in the CA1 area than in the CA3 area. Among CA1 subfields, the stratum oriens and stratum radiatum exhibited the highest concentrations of binding sites, whereas the number of sites was lowest in the stratum lacunosum moleculare. Muscarinic cholinergic receptors were also abundant in the molecular layer of the dentate gyrus (Table 2, Fig. 2, $A, B$ ).

In untreated ischemic gerbils, a large decrease in muscarinic receptors was observed in all subfields of the CA1 area (Fig. 2, $C, D$; Table 2) $16 \mathrm{~d}$ after carotid occlusion. This is entirely in accord with the previous histopathological observations. In contrast, muscarinic cholinergic receptors in the CA3 area and the dentate gyrus were not affected by carotid occlusion (Fig. 2, $C$, $D$; Table 2). Interestingly, the CA1 subfields displayed columnar bands of high and low densities of ${ }^{3} \mathrm{H}-\mathrm{QNB}$ binding sites (see

\begin{tabular}{|c|c|c|c|c|}
\hline Structures & Control $(n=5)$ & $\begin{array}{l}\text { Control + riluzole } \\
(n=5)\end{array}$ & Ischemic $(n=10)$ & $\begin{array}{l}\text { Ischemic + riluzole } \\
(n=7)\end{array}$ \\
\hline CA1 Or & $5.2 \pm 0.1$ & $5.3 \pm 0.1$ & $3.5 \pm 0.1^{* * *}$ & $4.3 \pm 0.2^{* *}, \dagger \dagger$ \\
\hline CA1 Rad & $6.2 \pm 0.1$ & $6.2 \pm 0.1$ & $4.3 \pm 0.2^{* * *}$ & $5.4 \pm 0.24^{*}+\dagger$ \\
\hline CA1 LMol & $4.9 \pm 0.2$ & $5.2 \pm 0.1$ & $3.6 \pm 0.1^{* * *}$ & $4.4 \pm 0.1+f^{+}$ \\
\hline $\mathrm{CA} 3$ & $4.2 \pm 0.1$ & $4.2 \pm 0.1$ & $4.0 \pm 0.1$ & $4.2 \pm 0.1$ \\
\hline DG & $5.5 \pm 0.1$ & $5.8 \pm 0.1$ & $5.6 \pm 0.1$ & $5.7 \pm 0.1$ \\
\hline
\end{tabular}

Binding densities were determined from autoradiograms as described in Materials and Methods. Values are expressed as pmol/mg protein and represent the means of $n$ animals \pm SEM. Significance of differences from control values: ${ }^{*} p$ $<0.05,{ }^{* *} p<0.01,{ }^{* * *} p<0.001$; from ischemic values: $+p<0.01 ;+\dagger+p<0.001$. CA1 Or, stratum oriens of the hippocampal CA1 field; CA1 Rad, stratum radiatum; CA1 LMol, stratum lacunosum moleculare; CA3, CA3 field of the hippocampus; DG, dentate gyrus. 

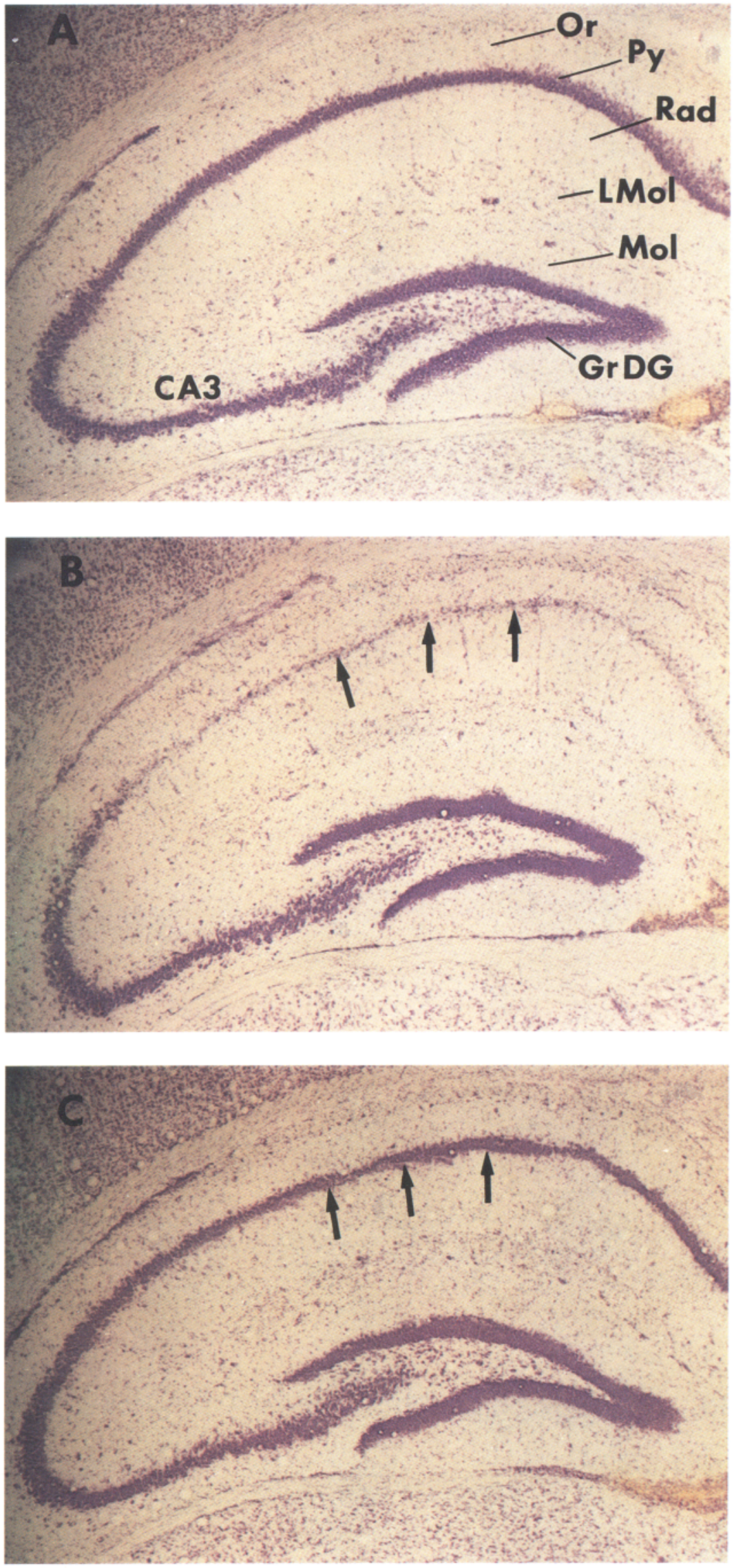

Figure 1. Coronal sections of the gerbil hippocampal formation stained with cresyl violet. $\times 25$. $A$, Control; $B, 16 \mathrm{~d}$ after bilateral carotid occlusion. Note the necrosis of the pyramidal cells (arrows). Neurons located in the CA3 area and the dentate gyrus are intact. $C$, After bilateral occlusion + riluzole treatment. Note the protection of the CA1 pyramidal cells. $O r$, stratum oriens; $P y$, pyramidal cell layer; $R a d$, stratum radiatum; $\mathrm{LMol}$, stratum lacunosum moleculare; $\mathrm{Mol}$, molecular layer of the dentate gyrus; $G r D G$, granule cell layer of the dentate gyrus. 


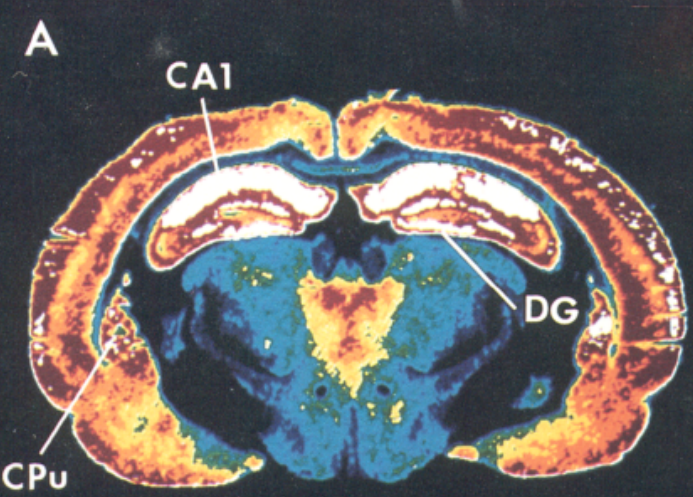

B

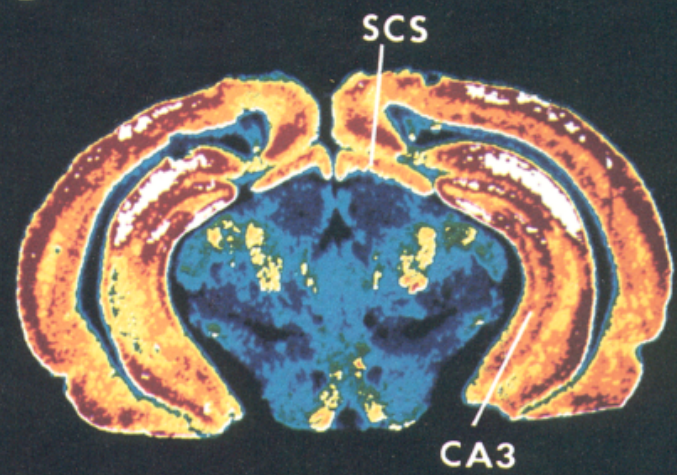

C

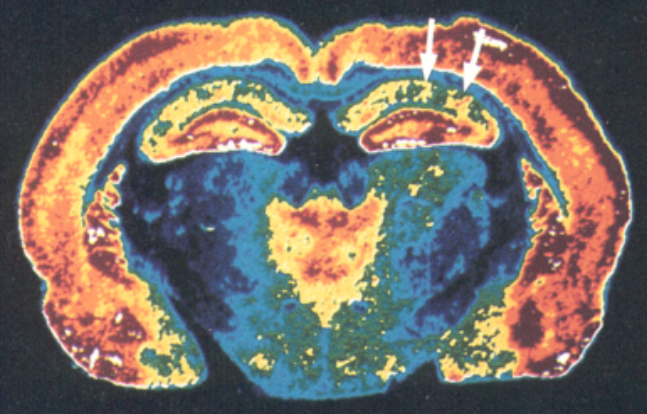

D

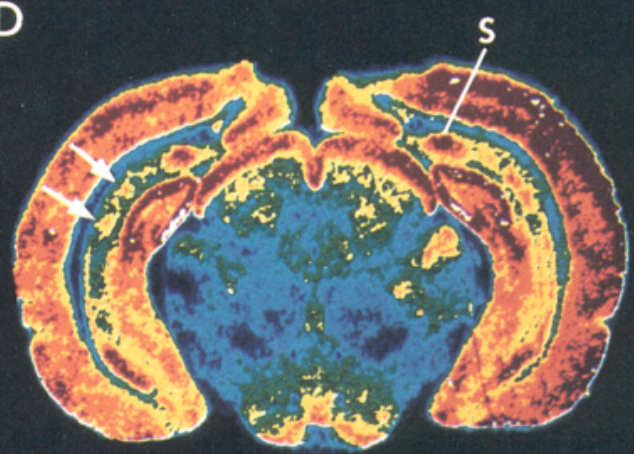

E

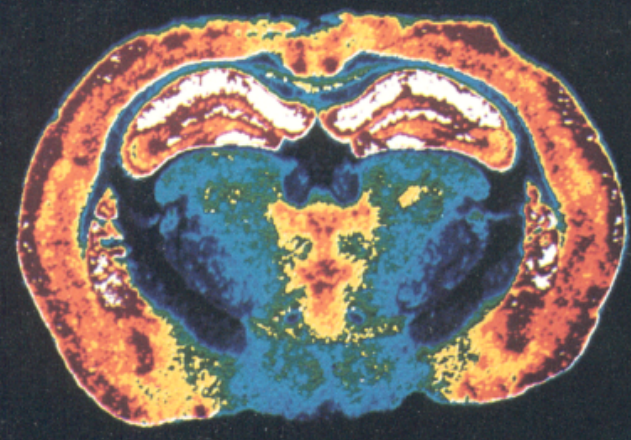

F
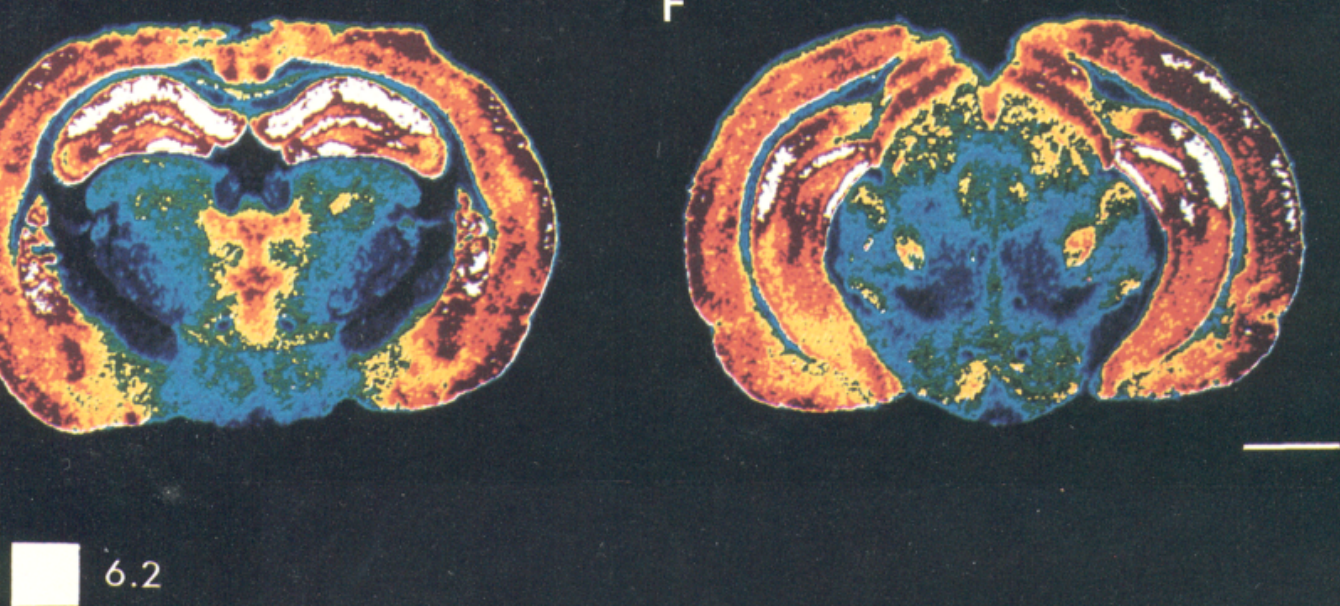

6.2

5.2

4.2

3.5

2.9

2.3

1.7

1.0

0.1 


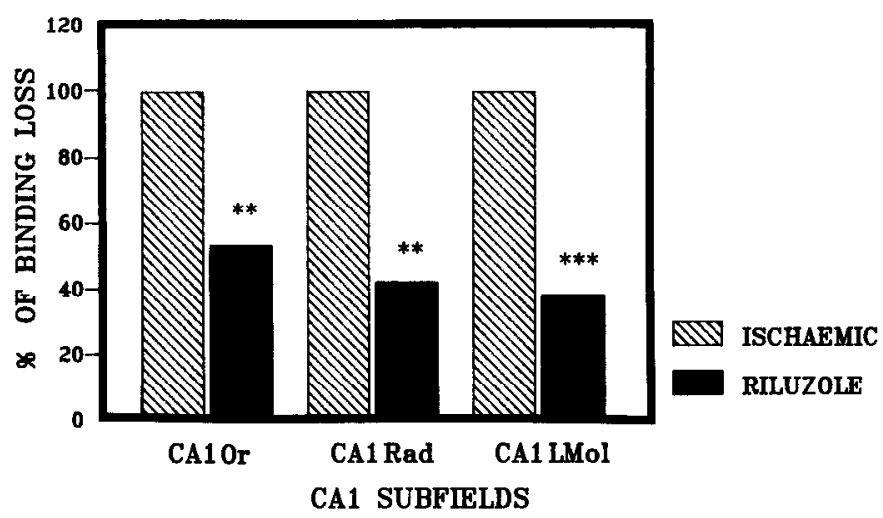

Figure 3. The protective effects of riluzole are presented in terms of the percentage of binding loss; with $100 \%$ corresponding to the maximal damage in untreated ischemic gerbils. Significant difference from ischemic values: ${ }^{* *} p<0.01 ;{ }^{* * *} p<0.001$.

arrows Fig. 2, C, D). Dense ${ }^{3} \mathrm{H}-\mathrm{QNB}$ labeling was also observed in the subiculum.

When riluzole $(4 \mathrm{mg} / \mathrm{kg})$ was given repeatedly to gerbils after carotid occlusion, the decrease in ${ }^{3} \mathrm{H}-\mathrm{QNB}$ binding sites in the $\mathrm{CA} 1$ subfields was clearly prevented by the drug (Fig. 2, E, F; Table 2). A highly significant protection against the loss of neuronal $\mathrm{QNB}$ binding was found in the stratum oriens, the stratum radiatum, and the lacunosum moleculare $(47,58,62 \%)$ in riluzole-treated gerbils (Fig. 3).

Interestingly, a significant correlation between the time latency detected in the memory test and the number of muscarinic cholinergic receptors was found for the CAl area $(R=0.83)$ but not in the dentate gyrus ( $R=0.05)$ (Fig. 4). It thus seems that the more pronounced memory deficits correspond to greater decreases in muscarinic receptors in the hippocampal CA1 area but not in the other hippocampal regions.

In order to exclude a possible interaction of riluzole with muscarinic receptors, relevant control experiments were performed; there were no differences in ${ }^{3} \mathrm{H}-\mathrm{QNB}$ binding in controls and control riluzole-treated animals (Table 2).

\section{Discussion}

In the present study, we have shown that riluzole, an antiglutamate drug, prevents the memory impairment induced by bilateral occlusion of the common carotid arteries in Mongolian gerbils. Moreover, in addition to this protective effect, riluzole could also prevent the neuronal loss revealed by histopathological examination and by the decrease of muscarinic cholinergic receptors in the CA1 subfields of the hippocampus. Indeed, the concomitant loss of neuronal cells observed morphologically and of ${ }^{3} \mathrm{H}-\mathrm{QNB}$ binding is compatible with the idea that the muscarinic receptors that disappeared after ischemia are located at least partly on neuronal cells. Consequently, 3 lines of evidence indicate that riluzole exerts a protective effect on hippocampal neurons: the functional test of memory, morpholog-

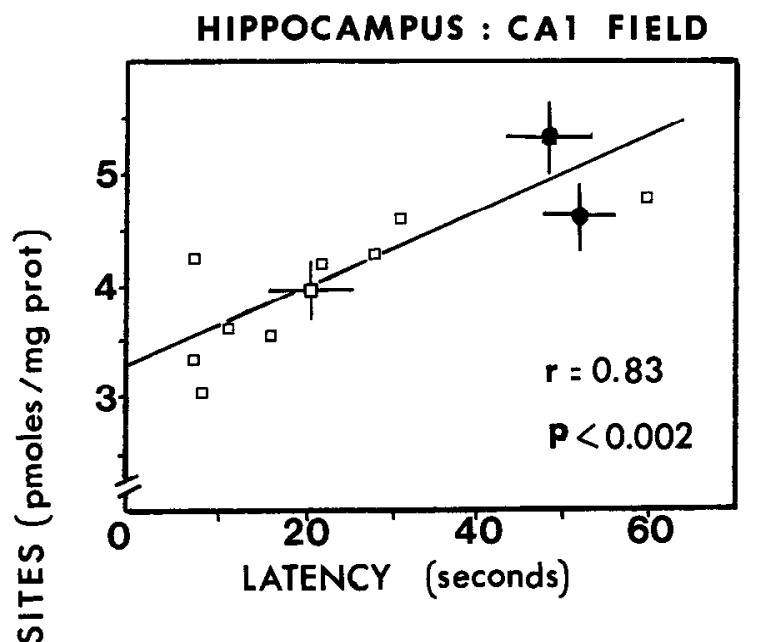

HIPPOCAMPUS: DENTATE GYRUS

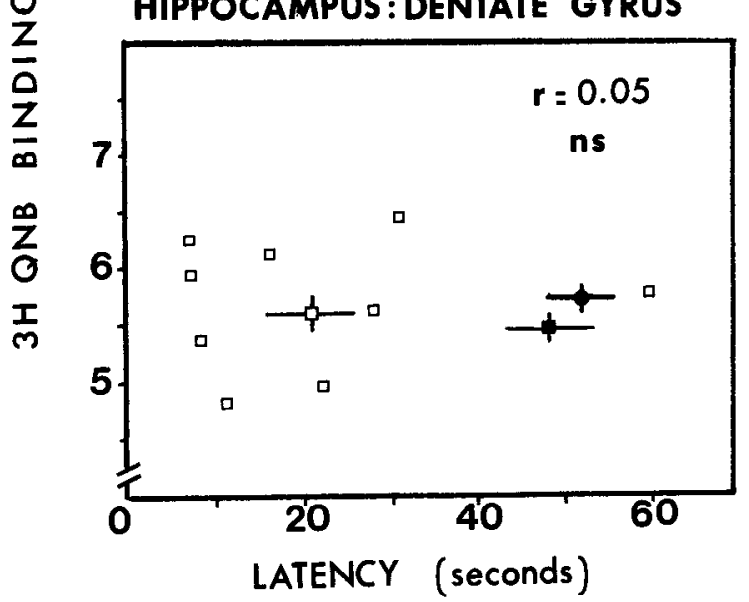

Figure 4. Correlation between time latency and muscarinic cholinergic receptors after carotid occlusion in different hippocampal regions: *, control (mean \pm SEM); th postocclusion (mean \pm SEM); $\square$, postocclusion (individual values); riluzole-treated gerbils (mean \pm SEM).

ical examination, and quantification of muscarinic receptors. This marked protective effect of riluzole was observed at a pharmacologically relevant, and relatively low, dose. At $2 \mathrm{mg} / \mathrm{kg}$, p.o., riluzole enhances slow-wave and REM sleep (Stutzmann et al., 1988) but does not produce either sedation, muscle relaxation, or hypothermia. The dose of $4 \mathrm{mg} / \mathrm{kg}$, i.p., used in this study corresponded to the one that had been found to protect rats from the convulsant effects of glutamic acid (Mizoule et al., 1985). Moreover, preliminary results indicate a protective effect of riluzole on memory impairment at the even lower dose of $1.25 \mathrm{mg} / \mathrm{kg}$, i.p. (data not shown).

As reported by several authors, many other compounds [barbiturates (Aitken and Schiff, 1986), ketamine (Rothman et al., 1987), chlorpromazine (Balestrino and Somjen, 1986), drugs interfering with the formation of oxygen-derived free radicals

Figure 2. Color-coded computer images from autoradiograms generated by apposition of $10 \mu \mathrm{m}$ sections incubated with $1 \mathrm{nM}{ }^{3} \mathrm{H}-\mathrm{QNB}$ to tritiumsensitive film under standard conditions (see Materials and Methods). Color-coded image of radioactive standards, as well as their respective concentrations, expressed in pmol/mg protein, are also shown. $A$ and $B,{ }^{3} \mathrm{H}-\mathrm{QNB}$ cholinergic muscarinic receptors from one control gerbil; $C$ and $D$, images from one gerbil with a bilateral carotid occlusion. Note the columnar pattern of high and low ${ }^{3} \mathrm{H}-\mathrm{QNB}$ binding in CA1 area (arrows); $E$ and $F$, images from one riluzole-treated gerbil. Abbreviations: $C A 1$, CA1 field of hippocampus; $C A 3, \mathrm{CA} 3$ field of hippocampus; $D G$, dentate gyrus; $S C S$, superficial layer of superior colliculus; $C P u$, caudate-putamen; $S$, subiculum. Scale bar, $2 \mathrm{~mm}$. 
(Taylor et al., 1985), and NMDA antagonists such as DL-2amino-7-phosphonoheptanoic acid (APH) (Simon et al., 1984) or MK 801 (Foster et al., 1987)] exert a protective effect against brain damage induced either by ischemia in situ or by hypoxia in vitro. Nevertheless, most of these are active at sedative doses. However, Aitken et al. (1988) was unable to demonstrate a protective effect of APH and DL-2-amino-5-phosphonovaleric acid (APV) in vitro against hypoxic damage in these $C A 1$ region of hippocampal slices. Thus, the precise mechanisms involved in the pathological events following ischemia or hypoxia are still open to question, particularly with regard to the role of glutamic acid. However, as reviewed by Siesjö (1988), many hypotheses have been proposed to explain the mechanism of neuronal death following ischemia. The entry of calcium into the cell is one of these, although definitive proof that the calcium transient induced by bilateral carotid occlusion has anything to do with the subsequent ischemic damage is still lacking. Indeed, calcium accumulation seems to occur only in vulnerable regions with dense neuronal necrosis (Dienel, 1984; Hossmann et al., 1985; Deshpande et al., 1987).

Another hypothesis, which is becoming more and more acceptablc, concerns the role of glutamic acid as the trigger of all the cellular events induced by ischemia (Rothman, 1984; Meldrum, 1985; Rothman and Olney, 1986). The present study confirms the fact that of the different brain regions, the CA1 subfields of the hippocampus, which receives glutamatergic innervation from the CA3 pyramidal cells (Schaffer collaterals), is the most sensitive to ischemic insult (Pulsinelli et al., 1982; Smith et al., 1984). This excitatory input from the CA3 pyramidal cells seems to play a critical role in CAl pyramidal cell death after carotid occlusion. Onodera et al. $(1986,1988)$ have demonstrated that kainic acid lesions of Schaffer collaterals prevent neuronal necrosis in the CA1 pyramidal cells after transient forebrain ischemia in gerbils. Our findings with riluzole, an antiglutamate compound, reinforce the idea that the release of glutamate is at least partly responsible for ischemic neuronal necrosis.

The fact that riluzole, which prevented neuronal damage in the CAl subfields of the hippocampus, does not possess calcium-antagonist activity, but antagonizes the pharmacological effects of glutamic acid may be considered as additional evidence for the role of glutamic acid release as a primary event in cerebral ischemia. These results also reinforce evidence accumulated in vitro and in vivo that, as stated by Rothman in 1986, "prevention of glutamatc rclcase or blockade of its postsynaptic action may protect central mammalian neurons from hypoxic ischemic injury."

Moreover, glutamic acid is believed to be the major transmitter of cortical and hippocampal pyramidal cells, and a number of workers have demonstrated severe losses of glutamatergic terminals in Alzheimer's disease (Palmer et al., 1986; Hardy et al., 1987; Cowburn et al., 1988).

These findings suggest that riluzole, which prevents memory impairment by exerting a protective effect against neuronal loss in the hippocampus of gerbils after bilateral carotid occlusion, may be a potential therapeutic agent in the treatment of irreversible brain damage developed after circulatory arrest and of neuronal degenerative disorders such as Alzheimer's disease and Parkinson's disease.

\section{References}

Aitken, P. G., and S. J. Schiff (1986) Barbiturate protection against hypoxic neuronal damage in vitro. J. Neurosurg. 65: 230-232.
Aitken, P. G., M. Balestrino, and G. G. Somjen (1988) NMDA antagonists: Lack of protective effect against hypoxic damage in CA1 region of hippocampal slices. Neurosci. Lett. 89: 187-192.

Araki, H., M. Nojiri, M. Kimura, and H. Aihara (1987) Effect of minaprine on "Delayed neuronal death" in Mongolian gerbils with occluded common carotid arteries. J. Pharmacol. Exp. Ther. 242: 686-691.

Balestrino, M., and G. G. Somjen (1986) Chlorpromazine protects brain tissue in hypoxia by delaying spreading depression-mediated calcium influx. Brain Res. 385: 219-226.

Benavides, J., J. C. Camelin, N. Mitrani, F. Flamand, A. Uzan, J. J. Legrand, C. Gueremy, and G. Le Fur (1985) 2-Amino-6-trifluoromethoxy benzothiazole, a possible antagonist of excitatory amino acid neurotransmission-II. Biochemical properties. Neuropharmacology 24: $1085-1092$.

Cheramy, A., R. Romo, G. Godeheu, P. Baruch, and J. Glowinski (1986) In vivo presynaptic control of dopamine release in the cat caudate nucleus. II. Facilitatory or inhibitory influence of L-glutamate. Neuroscience 19: 1018-1090.

Cowburn, R., J. Hardy, P. Roberts, and R. Briggs (1988) Presynaptic and postsynaptic glutamatergic function in Alzheimer's disease. Neurosci. Lett. 86: 109-113.

Deshpande, J. K., B. K. Siesjö, and T. Wieloch (1987) Calcium accumulation and neuronal damage in the rat hippocampus following cerebral ischemia. J. Cereb. Blood Flow Metab. 7: 89-95.

Dienel, G. A. (1984) Regional accumulation of calcium in postischemic rat brain. J. Neurochem. 43: 913-925.

Doble, A., J. P. Hubert, and M. L. Perrier (1987) The pharmacology of an excitatory amino acid receptor. Br. J. Pharmacol. 91: 23.

Drejer, J., T. Honore, E. Meier, and A. Schousboe (1986) Pharmacologically distinct glutamate receptors on cerebellar granule cells. Life Sci. 38: 2077-2085.

Evans, D. E., A. I. Kobrine, D. C. Legrys, and M. E. Bradle (1984) Protective effect of lidocaine in acute cerebral ischemia induced by air embolism. J. Neurochem. 43: 913-925.

Foster, A. C., R. Gill, J. A. Kemp, and G. N. Woodruff (1987) Systemic administration of MK-801 prevents N-methyl-D-aspartate-induced neuronal degeneration in rat brain. Neurosci. Lett. 76: 307-311.

Hagberg, H., A. Lehmann, M. Sandberg, B. Nyström, I. Jacobson, and A. Hamberger (1985) Ischemia-induced shift of inhibitory and excitatory amino acids from intra- to extracellular compartments. $\mathbf{J}$. Cereb. Blood Flow Metab. 5: 413-419.

Hardy, J. A., R. F. Cowburn, A. Barton, G. Reynolds, E. Lofdahl, A. M. O'Carroll, P. Wester, and B. Winblad (1987) Region-specific loss of glutamate innervation in Alzheimer's disease. Neurosci. Lett. 73: 77-80.

Hossmann, K. A., B. Grosse Ophoff, R. Schmidtkastner, and U. Oschlies (1985) Mitochondrial calcium sequestration in cortical and hippocampal neurons after prolonged ischaemia of the cat brain. Acta Neuropathol. (Berl.) 68: 230-238.

Jarrot, D. M., and F. R. Domer (1980) A gerbil model of cerebral ischemia suitable for drug evaluation. Stroke 11: 203-209.

Kirino, T. (1982) Delayed neuronal death in the gerbil hippocampus following ischemia. Brain Res. 239: 57-69.

Kuhar, M. J., and H. I. Yamamura (1976) Localization of cholinergic muscarinic receptors in rat brain by light microscopic autoradiography. Brain Res. 110: 229-243.

Levine, S., and H. Payan (1966) Effects of ischemia and other procedures on the brain and retina of the gerbil. Exp. Neurol. 16: 255262.

Meldrum, B. (1985) Excitatory amino acids and anoxic/ischaemic brain damage. Trends Neurosci. 8: 47-48.

Mizoule, J., B. Meldrum, M. Mazadier, M. Croucher, C. Ollat, A. Uzan, J. J. Legrand, C. Gueremy, and G. Le Fur (1985) 2-Amino-6-trifluoromethoxy benzothiazole, a possible antagonist of excitatory amino acid neurotransmission. I. Anticonvulsant properties. Neuropharmacology 24: 767-773.

Onodera, H., G. Sato, and K. Kogure (1986) Lesions to schaffer collaterals prevent ischemic death of CAI pyramidal cells. Neurosci. Lett. 68: 169-174.

Onodera, H., G. Sato, and K. Kogure (1987) Quantitative autoradiographic analysis of muscarinic cholinergic and adenosine Al binding sites after transient forebrain ischemia in the gerbil. Brain Res. 415: 309-322.

Onodera, H., T. Muneshige, and K. Kogure (1988) The effect of transient ischemia on 2-[14C] deoxyglucose metabolism in the rat hip- 
pocampus pretreated with kainic acid. Neurosci. Lett. 89: 90-96.

Palmer, A. M., A. W. Procter, G. C. Stratmann, and D. M. Bowen (1986) Excitatory amino acid releasing and cholinergic neurones in Alzheimer's disease. Neurosci. Lett. 66: 199-204.

Paxinos, G., and C. Watson (1986) The Rat Brain in Stereotaxic Coordinates, 2nd ed., Academic, New York.

Pulsinelli, W. A., J. B. Brierley, and F. Plum (1982) Temporal profile of neuronal damage in a model of transient forebrain ischemia. Ann. Neurol. 11: 491-498.

Rothman, S. M. (1984) Synaptic release of excitatory amino acid neurotransmitter mediates anoxic neuronal death. J. Neurosci. 4: 1884 1891.

Rothman, S. M., and J. W. Olney (1986) Glutamate and the pathophysiology of hypoxic-ischemic brain damage. Ann. Neurol. 19: 105111.

Rothman, S. M., J. H. Thurston, R. E. Hauhart, G. D. Clark, and J. S. Solomon (1987) Ketamine protects hippocampal neurons from anoxia in vitro. Neuroscience 21: 673-678.

Sicsjö, B. K. (1981) Cell damage in the brain: A speculative synthesis. J. Cerebr. Blood Flow. Metab. 1: 155-185.

Siesjö, B. K. (1988) Historical overview. Calcium, ischemia, and death of brain cells. Ann. NY Acad. Sci. 522: 638-661.
Simon, R. P., J. H. Swan, T. Griffiths, and B. S. Meldrum (1984) Blockade of $\mathrm{N}$-methyl-D-aspartate receptors may protect against ischemic damage in the brain. Science 226: 850-852.

Smith, M. L., R. N. Auer, and B. K. Siesjö (1984) The density and distribution of ischemic injury in the rat following 2-10 min of forebrain ischemia. Acta Neuropathol. 64: 319-332.

Stutzmann, J. M., M. Lucas, J. C. Blanchard, and P. M. Laduron (1988) Riluzole, a glutamate antagonist, enhances slow wave and REM sleep in rats. Neurosci. Lett. 88: 195-200.

Taylor, M. D., T. K. Mellert, J. L. Parmentier, and L. J. Eddy (1985) Pharmacological protection of reoxygenation damage to in vitro brain slice tissue. Brain Res. 347: 268-273.

Wamsley, J. K., M. A. Zarbin, and M. J. Kuhar (1984) Distribution of muscarinic cholinergic high and low affinity agonist binding sites: A light microscopic autoradiographic study. Brain Res. Bull. 12: 233 243.

Wieloch, T., and B. K. Siesjö (1982) Ischemic brain injury: The importance of calcium, lipolytic activity and free fatty acids. Pathol. Biol. (Paris) 30: 269-270. 